\title{
An update of teriflunomide for treatment of multiple sclerosis
}

This article was published in the following Dove Press journal:

Therapeutics and Clinical Risk Management

26 April 2013

Number of times this article has been viewed

\author{
Jiwon $\mathrm{Oh}^{1,2}$ \\ Paul W O'Connor ${ }^{2}$ \\ 'Department of Neurology, Johns \\ Hopkins University, Baltimore, MD \\ USA; ${ }^{2}$ Division of Neurology, \\ St Michael's Hospital, Toronto, \\ ON, Canada
}

Correspondence: Paul W O'Connor The MS Clinic at St Michael's Hospital, Shuter 3-003, 30 Bond Street, Toronto, ON M5B IW8, Canada

$\mathrm{Tel}+\mathrm{I} 4168645830$

Fax + I 4168645147

Email oconnorp@smh.ca

\begin{abstract}
There are a number of oral agents emerging as potential disease-modifying agents in multiple sclerosis (MS). Among these investigational agents, teriflunomide has shown promise in large, multicenter, phase III clinical trials with respect to safety and efficacy in relapsing MS patients, and is the latest disease-modifying agent approved for use in MS patients in the United States. This review will summarize teriflunomide's historical development, clinical pharmacology, studies in animals, clinical trials, and safety data, and will end with a discussion of the role of teriflunomide in MS in the context of existing treatment options.
\end{abstract}

Keywords: teriflunomide, multiple sclerosis, clinical trials, review

\section{Introduction}

Most of the available disease-modifying agents (DMAs) approved for use for the treatment of multiple sclerosis (MS) are administered parenterally, making the burden of medication administration substantial for patients. In recent years, a number of oral agents have emerged as potential therapeutic options in MS, with beneficial effects demonstrated in large, multicenter, phase III clinical trials. ${ }^{1}$ Teriflunomide $\left(\right.$ Aubagio $^{\circledR}$ ) is a novel oral drug that has shown promise with respect to clinical efficacy and safety in relapsing MS patients, and was recently approved by the Food and Drug Administration (FDA) of the United States of America for treatment of relapsing forms of MS. This review will clarify the role of teriflunomide in the context of current and emerging MS treatment options by summarizing relevant points on the use of teriflunomide in MS, with a discussion of teriflunomide's development, pharmacologic properties, animal studies and clinical trials, and safety and tolerability.

\section{Development of teriflunomide}

Teriflunomide is the principal active metabolite of leflunomide, which has been licensed for use in the treatment of rheumatoid arthritis (RA) for over a decade (Figure 1). ${ }^{2}$ Leflunomide was discovered in the 1980s during a chemical compound-screening process intended to identify agricultural pesticides, and was inadvertently found to have both anti-inflammatory and immunosuppressive properties, ${ }^{3}$ and was thus developed for use in RA. Due to its efficacy, safety, and tolerability in RA, leflunomide was later tested in animal models of other inflammatory disorders, including experimental autoimmune encephalitis, ${ }^{4}$ the animal model of MS. Upon oral ingestion, leflunomide is rapidly converted into its primary active metabolite, teriflunomide. Since teriflunomide 
Leflunomide

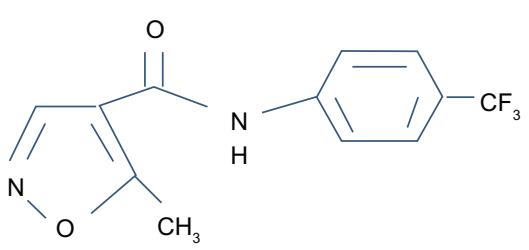

Figure I Related chemical structures of leflunomide and teriflunomide.

is able to avoid the first-pass metabolism that leflunomide undergoes, it has become the focus of development in MS patients.

\section{Clinical pharmacology: mechanism of action of teriflunomide}

The precise mechanisms by which teriflunomide exerts immunomodulatory effects in MS are incompletely understood. Teriflunomide primarily acts as an inhibitor of dihydroorotate dehydrogenase (DHODH), a key mitochondrial enzyme involved in the de novo synthesis of pyrimidines in rapidly proliferating cells. By reducing the activity of high-avidity proliferating $\mathrm{T}$ lymphocytes and $\mathrm{B}$ lymphocytes, teriflunomide likely attenuates the inflammatory response to autoantigens in MS. ${ }^{5}$ Of note, DHODH blockade does not affect resting or homeostatically proliferating hematopoietic cell lines, as pyrimidine pools in these cells can be generated through an alternate "salvage pathway," which is independent of the DHODH. ${ }^{6-9}$ As a result, basic homeostatic functions of resting and slowly dividing cells appear to be preserved, and lymphocytes remain available for immune surveillance. Thus, teriflunomide can be considered a cytostatic rather than a cytotoxic drug to leukocytes. In addition to DNA and RNA synthesis, pyrimidines are involved in a myriad of cellular functions, including protein and lipid glycosylation, phospholipid synthesis, ${ }^{10}$ and DNA strand repair, ${ }^{11}$ together which lead to a variety of downstream immunomodulatory effects (Figure 2).

Teriflunomide appears to have additional effects independent of DHODH inhibition, which likely account for a portion of its observed beneficial effects in MS. In vitro studies have demonstrated that in the presence of teriflunomide, exogenous reconstitution of pyrimidines will restore immune-cell proliferation, ${ }^{12}$ but other functions such as cytokine production, expression of cell-surface molecules, and cellular migration remain impaired. These observations suggest that teriflunomide has immunological effects outside of its ability to inhibit pyrimidine synthesis in rapidly proliferating cells. ${ }^{4,13}$
Teriflunomide

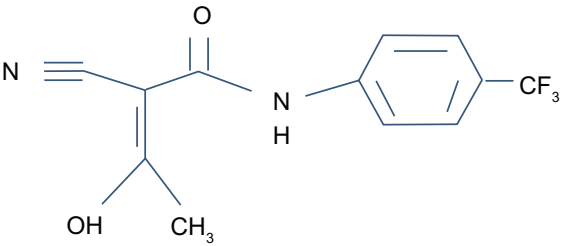

One identified DHODH-independent effect of teriflunomide is the inhibition of protein tyrosine kinases, which can result in a variety of downstream effects, including: a decrease in T-cell proliferation, diminished production of proinflammatory cytokines such as interferon (IFN)- $\gamma$ and interleukin 2, and inhibition of protein complexes such as nuclear factor kappa B. ${ }^{14-20}$ Another identified DHODHindependent effect of teriflunomide is its ability to inhibit the activity and expression of cyclooxygenase- $2,{ }^{21}$ and to reduce inducible nitric oxide synthase in astrocytes. ${ }^{20,22}$ Furthermore, there is evidence suggesting that teriflunomide modulates T-cell function by altering integrin function and intracellular calcium signaling, ${ }^{13,23,24}$ shifting the immune cytokine profile towards an anti-inflammatory T-helper 2 state, ${ }^{4,25}$ and by diminishing T-cell activation via antigen-presenting cells. ${ }^{23,26}$ Finally, teriflunomide may also affect components of the innate immune system by altering the function of adhesion molecules in neutrophils and macrophages, ${ }^{27-29}$ and by causing increased secretion of interleukin 10 by macrophages and microglia. ${ }^{4}$

Finally, a recent study has demonstrated that teriflunomide has the ability to inhibit intracellular polyglutamine protein aggregation in vitro, independently of its effects on pyrimidine biosynthesis. ${ }^{30}$ Abnormal protein aggregation

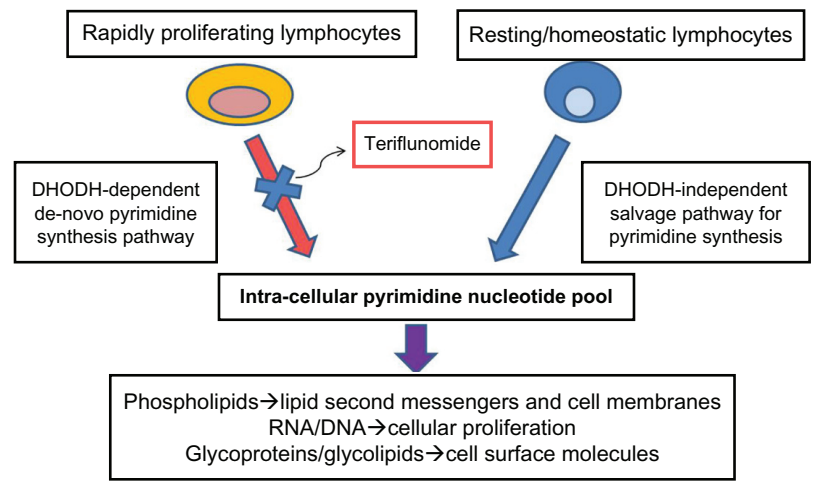

Figure 2 Mechanism of action of teriflunomide.

Note: Reprinted from Tallantyre, et al. Int MS J. 2008;15:62-68 with permission from Cambridge Medical Publications (CMP). ${ }^{33}$

Abbreviation: DHODH, dihydroorotate dehydrogenase. 
is a common pathological mechanism in a spectrum of neurodegenerative disorders, including Parkinson's disease and Huntington's disease. If confirmed, this suggests that teriflunomide may be of clinical utility in a broad spectrum of neurodegenerative neurological disorders.

Although many of these additional postulated effects of teriflunomide have been demonstrated in vitro and in animal models, the extent to which these mechanisms play a role in MS is unclear. Average steady-state maximum plasma concentrations $\left(\mathrm{C}_{\max }\right)$ of teriflunomide achieved with doses used in clinical trials are $168 \mu \mathrm{M}(14 \mathrm{mg})$ and $72 \mu \mathrm{M}(7 \mathrm{mg}){ }^{31}$ Concentrations of teriflunomide in vitro necessary to achieve its DHODH-independent mechanisms such as protein tyrosine kinase inhibition $(50-100 \mu \mathrm{M})^{12,31}$ and cyclooxygenase- 2 inhibition $(100-200 \mu \mathrm{M})^{21,31}$ are many orders of magnitude larger than what is necessary to achieve DHODH inhibition (1250 nM), ${ }^{8}$ making it entirely possible that these mechanisms may be of limited relevance in teriflunomide's clinical effects in MS. ${ }^{8,10}$

\section{Pharmacokinetics}

Food intake and hepatic impairment do not affect teriflunomide's pharmacokinetics, although concomitant food ingestion does impair the initial absorption. Teriflunomide's oral bioavailability is $\sim 100 \%$, with peak plasma levels observed within 1-2 hours of ingestion. Teriflunomide is $>99 \%$ protein-bound in plasma and demonstrates linear pharmacokinetics at a dose range of 7-100 mg/day, with a mean plasma half-life ranging between 10 and 12 days. $^{32}$ $\mathrm{C}_{\max }$ of teriflunomide is $45.3 \mu \mathrm{g} / \mathrm{mL}(14 \mathrm{mg}$ ) and $19.5 \mu \mathrm{g}$ / $\mathrm{mL}(7 \mathrm{mg})$, and there is a slow approach to steady state (3-3.25 months). ${ }^{31}$ Biliary and minor renal mechanisms contribute to drug clearance, thus washout procedures using cholestyramine or activated charcoal can facilitate clearance of teriflunomide. ${ }^{32,33}$

\section{Use of teriflunomide in animal models of multiple sclerosis}

Teriflunomide has demonstrated beneficial effects in two independent animal models of demyelinating disease. In the dark agouti rat model of experimental autoimmune encephalitis (EAE), which is a chronic animal model of demyelinating disease more reminiscent of relapsing MS in comparison to adoptive-transfer EAE, ${ }^{34-36}$ teriflunomide administration resulted in clinical, histopathological, and electrophysiological evidence of efficacy both as a prophylactic and therapeutic agent. From a clinical standpoint, teriflunomide delayed the onset of disease and reduced the maximal disability acquired in affected rats in comparison to controls. In animals already displaying clinical signs of disease, or in animals in disease remission, therapeutic doses of teriflunomide reduced maximal cumulative disability in comparison to controls. Corresponding pathological assessments of the rat spinal cords showed evidence of decreased inflammation, demyelination, and axonal loss with teriflunomide administration, which supported the observed clinical findings. From an electrophysiologic standpoint, in animals treated therapeutically with teriflunomide, somatosensoryevoked potentials demonstrated preserved wave amplitudes and wave latencies, both findings which support the clinical observations. ${ }^{37}$

Similarly, in the female Lewis rat model of EAE, which is another animal model of demyelinating disease, teriflunomide administration resulted in beneficial prophylactic and therapeutic clinical effects, with a delay in disease onset and symptom severity. ${ }^{38}$ Teriflunomide's demonstrated beneficial clinical effects in two independent animal models provides strong evidence supporting the efficacy of teriflunomide in animals, thereby supporting the experimental use of this agent in human clinical studies.

\section{Phase II clinical trials of teriflunomide in multiple sclerosis Safety and efficacy of teriflunomide in multiple sclerosis with relapses (NCT0I487096)}

Teriflunomide was first shown to be effective in MS in a phase II, multicenter, randomized, placebo-controlled, and double-blind trial that consisted of 179 relapsing MS patients (relapsing-remitting MS [RRMS] or progressive MS with superimposed relapses). Patients were required to be between 18 and 65 years of age, have an expanded disability status scale (EDSS) score $\leq 6.0$, and evidence of active disease demonstrated by the presence of two relapses in the past 3 years, one of which had taken place in the year prior to study enrollment. Patients were randomized in a 1:1:1 ratio to placebo, teriflunomide $7 \mathrm{mg}$ daily, or teriflunomide $14 \mathrm{mg}$ daily. These doses of teriflunomide were chosen based on experience with leflunomide.

The primary end point was the mean number of combined unique active lesions (CUALs) on magnetic resonance imaging (MRI), which was defined as either newly/persistently gadolinium-enhancing $T_{1}$ lesions $\left(T_{1}-\mathrm{Gd}\right)$ or new/enlarging $T_{2}$ hyperintense lesions. Secondary end points included clinical measures of disease activity, including relapse frequency 
and disability progression and additional MRI measures, including the number of $T_{1}$-Gd lesions, number of $T_{2}$ active lesions, number of patients with CUALs, $T_{1}$-Gd, and $T_{2}$ active lesions, and percentage change from baseline to end point in the burden of disease ( $T_{2}$ lesion volume). Participants underwent MRI scans every 6 weeks.

After 36 weeks, both teriflunomide treatment arms demonstrated a significant relative decrease in MRI activity in comparison to placebo, including fewer CUALs, $T_{1}$-Gd lesions, and new or enlarging $T_{2}$ lesions. The median number of CUALs per scan in comparison to placebo over the study period was 0.5 vs 0.2 vs 0.3 in the placebo, teriflunomide $7 \mathrm{mg}$ ( $P<0.03$ vs placebo), and teriflunomide $14 \mathrm{mg}$ groups ( $P<0.01$ vs placebo), respectively. The treatment effect on the primary end point was seen as early as 6 weeks, reached significance by 12 weeks, and was maintained throughout the duration of the study. Of note in this study, in order to achieve steady-state concentrations more rapidly, patients received double the maintenance dose of teriflunomide treatment during the first week of treatment. ${ }^{39}$

There was a trend towards a greater proportion of relapsefree patients in the $14 \mathrm{mg}$ teriflunomide treatment arm in comparison to placebo ( $77 \%$ vs $62 \%, P=0.098)$; however, the trial was not powered to assess clinical outcomes. The annualized relapse rates (ARRs) in both teriflunomide treatment arms were numerically lower in comparison to placebo, but the difference was not statistically significant. ${ }^{39}$ Furthermore, the proportion of patients with an EDSS score increase in comparison to baseline was $69 \%$ lower in the $14 \mathrm{mg}$ teriflunomide group in comparison to placebo ( $7.4 \%$ vs $21.3 \%, P=0.04)$.

\section{Long-term safety and efficacy of teriflunomide in multiple sclerosis with relapses (NCT00228163)}

An interim analysis of the open-label extension of the phase II trial followed 147 patients for a median duration of 7.1 years. Patients previously enrolled in one of the teriflunomide treatment arms continued on their original assigned dose ( $7 \mathrm{mg}$ or $14 \mathrm{mg}$ ), while those in the placebo arm were reallocated to one of the two doses of teriflunomide. The primary objective of this extension study was to evaluate the long-term safety and tolerability of teriflunomide in relapsing MS patients, while the secondary objective was to assess long-term clinical efficacy. Overall, teriflunomide showed a favorable safety and tolerability profile. Teriflunomide's clinical efficacy appeared to be maintained as the ARR in the study population remained low, and there was minimal disability progression. Furthermore, there was suggestion of a dose-dependent benefit on many MRI measures, including $T_{2}$ burden of disease, cerebral volume, new/enlarging $T_{2}$ lesions, and newly active lesions. Taken together, this study demonstrated that the beneficial clinical and radiological effects of teriflunomide observed in the phase II trial are maintained on a long-term basis. To date, this study provides the longest follow-up data of any existing oral DMA in MS. The long-term extension phase of this study is ongoing. ${ }^{40}$

Two phase II studies assessing the value of teriflunomide as add-on therapy to first-line injectable DMAs have been conducted. ${ }^{41,42}$

\section{Pilot study of teriflunomide as adjunctive therapy to IFN- $\beta$ in subjects with MS (NCT00489489)}

Teriflunomide as add-on therapy to IFN- $\beta$ was assessed in a multicenter, randomized, placebo-controlled, doubleblind clinical trial. 118 patients with relapsing MS (RRMS and relapsing forms of progressive MS) on a stable dose ( $>26$ weeks) of any of the available forms of IFN- $\beta$ (IFN- $\beta-1 \mathrm{a}$, I IFN- $\beta$-1b) were assigned in a 1:1:1 ratio to placebo, teriflunomide $7 \mathrm{mg}$, or teriflunomide $14 \mathrm{mg}$ in addition to IFN- $\beta$. The study treatment period was 24 weeks, with an optional 24-week extension phase. The primary objective was to evaluate the safety of teriflunomide as add-on therapy to IFN- $\beta$, and the secondary objectives were to evaluate the effect of treatment on various MRI measures and clinical activity. ${ }^{41}$

At 48 weeks, both teriflunomide doses as add-on treatment to IFN- $\beta$ demonstrated reduced MRI activity in comparison to IFN- $\beta$ alone, with a relative risk reduction of $84.6 \%$ $(P=0.0005)$ in the $7 \mathrm{mg}$ treatment group, and $82.8 \%$ in the $14 \mathrm{mg}$ treatment group $(P<0.0001)$ in the number of $T_{1}-\mathrm{Gd}$ lesions (number of $T_{1}$-Gd lesions per scan: 0.521, 0.080, 0.090 in placebo, $7 \mathrm{mg}$, and $14 \mathrm{mg}$ groups respectively). There was a corresponding relative reduction in $T_{1}$-Gd lesion volume of $72.1 \%(P=0.11)$ and $70.6 \%(P=0.02)$ in the $7 \mathrm{mg}$ and $14 \mathrm{mg}$ add-on treatment arms in comparison to IFN- $\beta$ alone (volume of $T_{1}$-Gd lesions per scan in milliliters: 0.068 , 0.019 , and 0.02 in placebo, $7 \mathrm{mg}$, and $14 \mathrm{mg}$ groups, respectively). Furthermore, there was a trend towards a reduction in ARR at 48 weeks when comparing the $14 \mathrm{mg}$ treatment arm to placebo ( 0.343 vs 0.144 ARR in placebo vs $14 \mathrm{mg}$ treatment arm, $P=0.10$ ), corresponding to a relative risk reduction of $32.6 \%$. A post hoc subgroup analysis suggested that in patients with more active disease at baseline (those who had at least one relapse in the previous year or $T_{1}$-Gd lesions at 
baseline) there was a more pronounced treatment effect with teriflunomide add-on treatment in comparison to those with less active disease at baseline. This finding is of interest, as it suggests that there may be a subgroup of patients that would benefit more from teriflunomide add-on therapy than others. ${ }^{41}$ An ongoing phase III clinical trial (TERACLES) will likely be able to assess this question more definitively. ${ }^{43}$

\section{Pilot study of teriflunomide as adjunctive therapy to GA in subjects with MS (NCT00475865)}

The utility of teriflunomide as add-on therapy to glatiramer acetate (GA) has been assessed in a multicenter, randomized, placebo-controlled, double-blind clinical trial of 123 relapsing MS patients on a stable dose of GA ( $>26$ weeks). The primary objective was to evaluate the safety of teriflunomide as add-on therapy to GA, and the secondary objectives were to evaluate treatment effects on various MRI measures and clinical activity. Enrolled patients were randomized in a 1:1:1 ratio to placebo, teriflunomide $7 \mathrm{mg}$ daily, or teriflunomide $14 \mathrm{mg}$ daily in addition to GA for a treatment period of 24 weeks, with an optional 24-week extension phase.

At 24 weeks, teriflunomide as add-on therapy to GA showed acceptable safety and tolerability, and possibly improved disease control based on MRI measures. In comparison to GA alone, there was a decrease in the number of $T_{1}$-Gd lesions $(P=0.03)$ in the $7 \mathrm{mg}$ teriflunomide add-on treatment group, and a decrease in the volume of $T_{1}$-Gd lesions in the $14 \mathrm{mg}$ teriflunomide add-on treatment group $(P=0.04)$. However, further study is necessary to more definitely assess the safety and clinical benefit of teriflunomide as add-on therapy to GA. ${ }^{42}$

A 24-week extension of both phase II add-on trials of teriflunomide to either IFN- $\beta$ or GA has been completed, with results pending. ${ }^{44}$

\section{Study to investigate the immune response to influenza vaccine in patients with multiple sclerosis on teriflunomide (TERIVA) (NCTOI403376)}

The ability of relapsing MS patients taking teriflunomide to respond to the influenza vaccine was assessed in a multicenter, multinational, parallel-group study of 128 individuals. The primary end point was the proportion of patients who achieved seroprotection to influenza vaccine strains H1N1, $\mathrm{H} 3 \mathrm{~N} 2$, and $\mathrm{B}$ at 28 days postvaccination. The safety of the influenza vaccine in teriflunomide-treated patients was also assessed. Patients were enrolled in one of three groups: groups 1 and 2 included patients with relapsing MS treated for $\geq 6$ months with either teriflunomide $7 \mathrm{mg}$ or $14 \mathrm{mg}$ at the time of inclusion, and group 3 consisted of patients with relapsing MS treated for at least 6 months on a stable dose of IFN- $\beta$. After the screening period, all enrolled patients received the influenza vaccine, and antibody titers were assessed at day 28 .

After 28 days, MS patients treated with teriflunomide mounted effective immune responses to the seasonal influenza vaccine. Patients in the reference group treated with IFN- $\beta$ mounted an effective immune response to influenza vaccine, as expected. Furthermore, there were no new safety concerns identified in patients treated with teriflunomide following influenza vaccination (see Table 1$).{ }^{45}$

\section{Phase III clinical trials of teriflunomide in multiple sclerosis}

\section{Study of teriflunomide in reducing the frequency of relapses and accumulation of disability in patients with MS (TEMSO) (NCT00 I 34563)}

The Teriflunomide Multiple Sclerosis Oral (TEMSO) trial was the first Phase III clinical trial assessing the efficacy of teriflunomide in MS patients. TEMSO was a multicenter, randomized, placebo-controlled, double-blind, phase III clinical trial. The primary goal was to assess the clinical efficacy of teriflunomide in relapsing MS patients. Enrolled patients had relapsing MS, were between the ages of 18 and 55 years, had EDSS scores $\leq 5.5$, and evidence of active disease (at least two clinical relapses in the preceding 2 years, or at least one relapse in the previous year). A total of 1088 patients were randomly assigned in a 1:1:1 ratio to placebo, teriflunomide $7 \mathrm{mg}$ daily, or teriflunomide $14 \mathrm{mg}$ daily. The study treatment period was 108 weeks. The primary end point of the trial was the ARR, and secondary end points included sustained disability progression (defined a priori as the key secondary end point) and various MRI measures of disease activity, including total lesion volume, number of unique active lesions, $T_{1}$-Gd lesions, $T_{1}$-hypointense lesions and brain atrophy, and fatigue. ${ }^{46}$

At 108 weeks, patients in both teriflunomide treatment groups had diminished ARR in comparison to placebo $(0.54$ for placebo arm, 0.37 for both teriflunomide treatment arms), corresponding to relative risk reductions of $31.2 \%$ and $31.5 \%$ in the $7 \mathrm{mg}$ and $14 \mathrm{mg}$ groups respectively $(P<0.001)$, in comparison to placebo. Furthermore, both teriflunomide 
Table I Phase II clinical trials of teriflunomide in multiple sclerosis

\begin{tabular}{|c|c|c|c|}
\hline $\begin{array}{l}\text { Clinical trial name } \\
\text { (ClinicalTrials.gov identifier) }\end{array}$ & Study phase/design & Study participants & Study arms \\
\hline $\begin{array}{l}\text { Safety and efficacy } \\
\text { of teriflunomide } \\
\text { in MS with relapses } \\
\text { (NCT0I487096) }\end{array}$ & $\begin{array}{l}\text { Phase II } \\
\text { Multicenter, randomized, } \\
\text { placebo-controlled, } \\
\text { double-blind, } \\
\text { parallel-group }\end{array}$ & $\begin{array}{l}\text { Relapsing MS } \\
\mathrm{n}=179\end{array}$ & $\begin{array}{l}\text { Placebo } \\
\text { Teriflunomide } 7 \mathrm{mg} \\
\text { Teriflunomide } 14 \mathrm{mg}\end{array}$ \\
\hline $\begin{array}{l}\text { Pilot study of teriflunomide } \\
\text { as adjunctive therapy to } \\
\text { IFN- } \beta \text { in subjects with MS } \\
\text { (NCT00489489) }\end{array}$ & $\begin{array}{l}\text { Phase II } \\
\text { Multicenter, randomized, } \\
\text { placebo-controlled, } \\
\text { double-blind, parallel-group }\end{array}$ & $\begin{array}{l}\text { Relapsing MS on stable dose } \\
\text { of IFN- } \beta \text { ( }>26 \text { weeks) } \\
n=118\end{array}$ & $\begin{array}{l}\text { IFN- } \beta+\text { placebo } \\
\text { IFN- } \beta+\text { teriflunomide } 7 \mathrm{mg} \\
\text { IFN- } \beta \text { + teriflunomide } 14 \mathrm{mg}\end{array}$ \\
\hline $\begin{array}{l}\text { Pilot study of teriflunomide } \\
\text { as adjunctive therapy to } \\
\text { GA in subjects with MS } \\
\text { (NCT00475865) }\end{array}$ & $\begin{array}{l}\text { Phase II } \\
\text { Multicenter randomized, } \\
\text { placebo-controlled, } \\
\text { double-blind, parallel-group }\end{array}$ & $\begin{array}{l}\text { Relapsing MS on stable } \\
\text { dose of GA ( }>26 \text { weeks) } \\
n=123\end{array}$ & $\begin{array}{l}\mathrm{GA}+\text { placebo } \\
\mathrm{GA}+\text { teriflunomide } 7 \mathrm{mg} \\
\mathrm{GA}+\text { teriflunomide } 14 \mathrm{mg}\end{array}$ \\
\hline $\begin{array}{l}\text { Long-term safety of teriflunomide } \\
\text { when added to IFN- } \beta \text { or } \\
\text { glatiramer acetate } \\
\text { in patients with MS } \\
\text { (NCT008I I395) }\end{array}$ & $\begin{array}{l}\text { Phase II } \\
\text { Multicenter randomized, } \\
\text { placebo-controlled, double-blind, } \\
\text { parallel-group }\end{array}$ & $\begin{array}{l}\text { Relapsing MS with completion } \\
\text { of phase II IFN- } \beta \text { or } \\
\text { GA add-on studies } \\
n=182\end{array}$ & $\begin{array}{l}\text { IFN- } \beta \text { + placebo } \\
\text { IFN- } \beta \text { + teriflunomide } 7 \mathrm{mg} \\
\text { IFN- } \beta \text { + teriflunomide } 14 \mathrm{mg} \\
\text { GA + placebo } \\
\text { GA + teriflunomide } 7 \mathrm{mg} \\
\text { GA + teriflunomide } 14 \mathrm{mg}\end{array}$ \\
\hline $\begin{array}{l}\text { Long-term safety and } \\
\text { efficacy of teriflunomide } \\
(\text { HMRI } 726) \text { in MS } \\
\text { with relapses } \\
\text { (NCT00228I63) }\end{array}$ & $\begin{array}{l}\text { Phase II } \\
\text { Multicenter, randomized, } \\
\text { open-label, parallel-group }\end{array}$ & $\begin{array}{l}\text { Relapsing MS with completion of } \\
\text { phase II monotherapy study } \\
\begin{array}{l}n=180 \text { (estimated); } \\
n=147 \text { (interim) }\end{array}\end{array}$ & $\begin{array}{l}\text { Teriflunomide } 7 \text { mg daily } \\
\text { Teriflunomide } 14 \text { mg daily }\end{array}$ \\
\hline $\begin{array}{l}\text { Study to investigate the immune } \\
\text { response to influenza vaccine } \\
\text { in patients with multiple } \\
\text { sclerosis on teriflunomide } \\
\text { (TERIVA) (NCTOI403376) }\end{array}$ & $\begin{array}{l}\text { Phase II } \\
\text { Multicenter, multinational, } \\
\text { parallel-group }\end{array}$ & $\begin{array}{l}\text { Relapsing MS treated for } \geq 6 \\
\text { months with: teriflunomide } 7 \mathrm{mg} \\
\text { or } 14 \mathrm{mg} \text {, stable dose of IFN- } \beta\end{array}$ & $\begin{array}{l}\text { Teriflunomide } 7 \mathrm{mg}+\text { influenza } \\
\text { vaccine } \\
\text { Teriflunomide } 14 \mathrm{mg}+\text { influenza } \\
\text { vaccine } \\
\text { IFN- } \beta+\text { influenza vaccine }\end{array}$ \\
\hline
\end{tabular}

Abbreviations: MS, multiple sclerosis; MRI, magnetic resonance imaging; CUAL, combined unique active lesions; IFN- $\beta$, interferon-beta; ARR, annualized relapse rate; Rx, treatment; $T_{1}$-Gad, gadolinium-enhancing lesions on $T_{1}$-weighted sequence on MRI; GA, glatiramer acetate; EDSS, expanded disability status scale; MSFC, multiple sclerosis functional composite.

treatment arms had diminished proportions of patients with 12-week confirmed disability progression in comparison to the placebo arm $(27.3 \%, 21.7 \%$, and $20.2 \%$ for placebo, $7 \mathrm{mg}$, and $14 \mathrm{mg}$ arms; log-rank $P$-value $7 \mathrm{mg}, P=0.08,14 \mathrm{mg}$, $P=0.03$ ). Both teriflunomide treatment arms had improved MRI-related measures of disease activity in comparison to placebo. Specifically, in comparisons of the $7 \mathrm{mg}$ and $14 \mathrm{mg}$ teriflunomide treatment groups to placebo, the change in total lesion volume was significantly lower $(P=0.03$ and $P<0.001$, respectively), there were fewer $T_{1}$-Gd lesions per MRI scan ( $P<0.001$ for both comparisons), and there were fewer unique active lesions per scan $(P<0.001$ for both comparisons). There were no differences among study arms in brain-atrophy change, or change in fatigue in comparison to baseline (as measured by the fatigue impact scale). ${ }^{46}$

Overall, TEMSO confirmed clinical findings from the previous phase II trial, in addition to the safety and tolerability of teriflunomide. There is an ongoing open-label extension of TEMSO, which will continue until teriflunomide is commercially available in the patient's country of residence. ${ }^{47}$

At present, there are several ongoing phase III and long-term extension clinical trials designed to confirm the efficacy, safety, and tolerability of teriflunomide in MS patients as monotherapy or as add-on therapy to existing DMAs.

\section{An efficacy study of teriflunomide in patients with relapsing $M S$ (TOWER) (NCT0075I 88I)}

The Teriflunomide Oral in People with Relapsing-Remitting Multiple Sclerosis (TOWER) study is the second large, multicenter, randomized, placebo-controlled, double-blind, phase III clinical trial that evaluated the efficacy and safety 


\begin{tabular}{|c|c|c|}
\hline $\begin{array}{l}\text { Treatment } \\
\text { period }\end{array}$ & Primary/key secondary outcomes & Results \\
\hline 36 weeks & $\begin{array}{l}\text { Primary: CUALs per MRI } \\
\text { Secondary: other MRI outcomes, relapse frequency, } \\
\text { disability progression, safety, and tolerability }\end{array}$ & $\begin{array}{l}\text { Decrease in CUALs in both Rx groups } \\
\text { Decrease in other MRI outcomes in both Rx groups } \\
\text { Decrease in disability progression in } 14 \mathrm{mg} \mathrm{Rx} \text { group, } \\
\text { trend towards a decrease in } 7 \mathrm{mg} \text { group } \\
\text { Well tolerated }\end{array}$ \\
\hline 24 weeks & $\begin{array}{l}\text { Primary: number of patients with adverse events, } \\
\text { clinically significant abnormalities } \\
\text { Secondary: ARR, MRI outcomes }\end{array}$ & $\begin{array}{l}\text { Well tolerated } \\
\text { Reduced number of } T_{1}-\text { Gd lesions both } \mathrm{Rx} \text { groups } \\
T_{1} \text {-Gd lesion volume reduced in } 14 \mathrm{mg} \mathrm{Rx} \text { groups } \\
\text { Trend towards reduced ARR in high-dose Rx group }\end{array}$ \\
\hline 24 weeks & $\begin{array}{l}\text { Primary: number of patients with adverse events } \\
\text { Secondary: ARR, MRI outcomes, fatigue }\end{array}$ & $\begin{array}{l}\text { Acceptable safety } \\
\text { Decrease in } T_{1}-\text { Gd lesion count in } 7 \mathrm{mg} \text { Rx group } \\
\text { Decrease in } T_{1}-\text {-Gd volume in } 14 \mathrm{mg} \text { Rx group }\end{array}$ \\
\hline 24 weeks & $\begin{array}{l}\text { Primary: number of patients with adverse events } \\
\text { Secondary: ARR, disability progression, MRI outcomes }\end{array}$ & Pending \\
\hline 528 weeks & $\begin{array}{l}\text { Primary: number of patients with adverse events } \\
\text { Secondary: ARR, disability accumulation } \\
\text { (EDSS, MSFC), MRI outcomes, quality of life, fatigue }\end{array}$ & $\begin{array}{l}\text { Recruitment complete, active. Interim results: favorable safety profile } \\
\text { - Low annualized relapse rates } \\
\text { - Minimal disability progression } \\
\text { - Dose-dependent benefit with high-dose Rx for several MRI } \\
\text { outcomes }\end{array}$ \\
\hline 28 days & $\begin{array}{l}\text { Primary: proportion of patients who achieved } \\
\text { seroprotection to influenza vaccine strains HINI, } \\
\mathrm{H} 3 \mathrm{~N} 2 \text {, and B at } 28 \text { days postvaccination }\end{array}$ & $\begin{array}{l}\text { MS patients treated with teriflunomide mounted effective immune } \\
\text { responses to the seasonal influenza vaccination } \\
\text { As expected, MS patients in the reference IFN- } \beta \text { group mounted an } \\
\text { effective immune response to influenza vaccine } \\
\text { No new safety concerns identified in patients treated with } \\
\text { teriflunomide following influenza vaccination }\end{array}$ \\
\hline
\end{tabular}

of teriflunomide in patients with relapsing MS. Enrolled patients $(n=1169)$ were randomized in a $1: 1: 1$ ratio to placebo, teriflunomide $7 \mathrm{mg}$, or teriflunomide $14 \mathrm{mg}$. The primary outcome measure was ARR, while secondary outcome measures included time to disability progression (defined a priori as the key secondary outcome), change in fatigue, and change in health status (as measured by the Short Form 36 Health Survey). Top-line results of TOWER presented recently are in keeping with what was observed in TEMSO.

There was a significant decrease in ARR in both the $7 \mathrm{mg}$ and $14 \mathrm{mg}$ teriflunomide treatment arms in comparison to placebo $(22.3 \%[P=0.02]$ and $36.3 \%[P<0.0001]$, respectively). In the $14 \mathrm{mg}$ treatment arm, there was a $31.5 \%$ reduction in the risk of 12 -week sustained disability accumulation in comparison to placebo $(P=0.04)$, while there was no statistically significant difference in the $7 \mathrm{mg}$ treatment arm. ${ }^{48}$
Further results of this study are expected to be presented in the upcoming months.

\section{A study comparing the effectiveness and safety of teriflunomide and IFN- $\beta$ - Ia in patients with relapsing MS (TENERE) (NCT00883337)}

The Teriflunomide and IFN- $\beta-1 \mathrm{a}$ in Patients with Relapsing Multiple Sclerosis (TENERE) study is a randomized, phase III, multicenter, rater-blinded, parallel-group trial that aims to compare the efficacy of two doses of teriflunomide to IFN- $\beta-1 \mathrm{a}$ (Rebif) in relapsing MS patients. RRMS patients $(n=324)$ with EDSS scores $\leq 5.5$ were randomized in a $1: 1: 1$ ratio to oral teriflunomide $7 \mathrm{mg}$ daily, teriflunomide $14 \mathrm{mg}$ daily, or IFN- $\beta$-1a (Rebif) subcutaneously at $44 \mu \mathrm{g}$ three times weekly.

The primary outcome measure was risk of failure, which was defined as the first occurrence of relapse or permanent 
study treatment discontinuation for any cause. Secondary outcome measures included: ARR, fatigue (measured by the fatigue impact scale), and subject satisfaction (assessed by the treatment satisfaction questionnaire for medication).

There was no statistical superiority of either dose of teriflunomide over Rebif in the primary end point of treatment failure. In addition, the $14 \mathrm{mg}$ teriflunomide group and IFN- $\beta$ - 1 a treatment group were numerically similar with respect to ARR ( 0.259 vs 0.216 , respectively), while the $7 \mathrm{mg}$ teriflunomide group had a higher ARR (0.410), suggesting that high-dose teriflunomide treatment may be similar to IFN- $\beta-1$ a with respect to clinical efficacy measures in MS. The rate of permanent treatment discontinuation was lower in both teriflunomide treatment arms vs the IFN- $\beta$-1a group $(18.3 \%, 19.8 \%$, and $28.8 \%$ of subjects, in teriflunomide $7 \mathrm{mg}, 14 \mathrm{mg}$, and placebo, respectively). ${ }^{49}$

Further results of this study are expected to be presented in the near future.
Efficacy and safety of teriflunomide in patients with relapsing $M S$ and treated with IFN- $\beta$ (TERACLES) (NCTOI252355)

The Efficacy and Safety to Teriflunomide in Patients with Relapsing MS and Treated with IFN- $\beta$ (TERACLES) study is a phase III, multicenter, randomized, placebo-controlled, double-blind, parallel-group trial currently enrolling patients that aims to evaluate the efficacy and safety of teriflunomide as add-on therapy to any of the IFN- $\beta$ class of drugs (including IFN- $\beta-1 \mathrm{a}$ and IFN- $\beta-1 \mathrm{~b})$. The estimated number of patients that will eventually be enrolled in this study is 1455 .

\section{Phase III study with teriflunomide versus placebo in patients with first clinical symptom of MS (TOPIC) (NCT00622700)}

Finally, the Teriflunomide Versus Placebo in Patients with First Clinical Symptom of Multiple Sclerosis (TOPIC) study

Table 2 Phase III clinical trials of teriflunomide in multiple sclerosis

\begin{tabular}{|c|c|c|c|}
\hline Clinical trial name & Study phase/design & Study participants & Study arms \\
\hline $\begin{array}{l}\text { Study of teriflunomide in reducing } \\
\text { the frequency of relapses and } \\
\text { accumulation of disability in } \\
\text { patients with MS (TEMSO) } \\
\text { (NCT00 I 34563) }\end{array}$ & $\begin{array}{l}\text { Phase III } \\
\text { Multicenter, randomized, } \\
\text { placebo-controlled, } \\
\text { double-blind, } \\
\text { parallel-group }\end{array}$ & $\begin{array}{l}\text { Relapsing MS } \\
\mathrm{n}=1088\end{array}$ & $\begin{array}{l}\text { Placebo } \\
\text { Teriflunomide } 7 \mathrm{mg} \\
\text { Teriflunomide } 14 \mathrm{mg}\end{array}$ \\
\hline $\begin{array}{l}\text { An efficacy study of teriflunomide } \\
\text { in patients with relapsing MS (TOWER) } \\
\text { (NCT0075I88I) }\end{array}$ & $\begin{array}{l}\text { Phase III } \\
\text { Multicenter, randomized, } \\
\text { placebo-controlled, double- } \\
\text { blind, parallel-group }\end{array}$ & $\begin{array}{l}\text { Relapsing MS } \\
\mathrm{n}=\mathrm{III0} \text { (estimated) }\end{array}$ & $\begin{array}{l}\text { Placebo } \\
\text { Teriflunomide } 7 \mathrm{mg} \\
\text { Teriflunomide } 14 \mathrm{mg}\end{array}$ \\
\hline $\begin{array}{l}\text { A study comparing the effectiveness } \\
\text { and safety of teriflunomide and } \\
\text { IFN- } \beta \text { - Ia in patients with } \\
\text { relapsing MS (TENERE) } \\
\text { (NCT00883337) }\end{array}$ & $\begin{array}{l}\text { Phase III } \\
\text { Multicenter, randomized, } \\
\text { rater-blinded, parallel-group }\end{array}$ & $\begin{array}{l}\text { Relapsing MS } \\
\mathrm{n}=300 \text { (estimated) }\end{array}$ & $\begin{array}{l}\text { IFN } \beta \text { - Ia } 44 \text { SC TIW } \\
\text { Teriflunomide } 7 \mathrm{mg} \\
\text { Teriflunomide } 14 \mathrm{mg}\end{array}$ \\
\hline $\begin{array}{l}\text { Long-term safety and efficacy } \\
\text { study of teriflunomide } 7 \mathrm{mg} \text { or } \\
\mathrm{I} 4 \mathrm{mg} \text { in patients with } \\
\text { relapsing-remitting MS } \\
\text { (TEMSO) } \\
\text { (NCT00803049) }\end{array}$ & $\begin{array}{l}\text { Phase III } \\
\text { Multicenter, randomized, } \\
\text { double-blind, parallel-group }\end{array}$ & $\begin{array}{l}\text { Relapsing MS with } \\
\text { completion of TEMSO } \\
n=1080 \text { (estimated) }\end{array}$ & $\begin{array}{l}\text { Teriflunomide } 7 \mathrm{mg} \\
\text { Teriflunomide } 14 \mathrm{mg}\end{array}$ \\
\hline $\begin{array}{l}\text { Efficacy and safety of teriflunomide } \\
\text { in patients with relapsing MS } \\
\text { and treated with IFN- } \beta \text { (TERACLES) } \\
\text { (NCTOI252355) }\end{array}$ & $\begin{array}{l}\text { Phase III } \\
\text { Multicenter, randomized, } \\
\text { placebo-controlled, double- } \\
\text { blind, parallel-group }\end{array}$ & $\begin{array}{l}\text { Relapsing MS on stable dose } \\
\text { of IFN- } \beta \text { ( }>6 \text { months), with } \\
\text { disease activity } \\
\mathrm{n}=1455 \text { (estimated) }\end{array}$ & $\begin{array}{l}\text { IFN- } \beta+\text { placebo } \\
\text { IFN- } \beta+\text { teriflunomide } 7 \mathrm{mg} \\
\text { IFN- } \beta+\text { teriflunomide } 14 \mathrm{mg}\end{array}$ \\
\hline $\begin{array}{l}\text { Phase III study with teriflunomide } \\
\text { versus placebo in patients with } \\
\text { first clinical symptom of MS (TOPIC) } \\
\text { (NCT00622700) }\end{array}$ & $\begin{array}{l}\text { Phase III } \\
\text { Multicenter, randomized, } \\
\text { placebo-controlled, double- } \\
\text { blind, parallel-group }\end{array}$ & $\begin{array}{l}\text { First clinical episode suggestive } \\
\text { of MS within } 90 \text { days of } \\
\text { randomization and MRI with }>2 \\
\text { lesions characteristic of MS } \\
n=618\end{array}$ & $\begin{array}{l}\text { Placebo } \\
\text { Teriflunomide } 7 \mathrm{mg} \\
\text { Teriflunomide } 14 \mathrm{mg}\end{array}$ \\
\hline
\end{tabular}

Abbreviations: MS, multiple sclerosis; MRI, magnetic resonance imaging; ARR, annualized relapse rate; IFN- $\beta$, interferon-beta; Rx, treatment; CDMS, clinically definite multiple sclerosis; SC, subcutaneous; TIW, three times a week. 
is an ongoing phase III, multicenter, randomized, placebocontrolled, double-blind, parallel-group clinical trial enrolling patients with first episodes of demyelination highly suggestive of MS, but not satisfying current diagnostic criteria. This study aims to evaluate the efficacy of teriflunomide for preventing relapses in these patients, and thereby preventing/ delaying conversion to clinically definite MS. Enrollment in this study is now complete $(\mathrm{n}=618)$ ( see Table 2$).{ }^{50}$

\section{Safety and tolerability}

Teriflunomide is generally a well-tolerated drug, with predominately mild to moderate treatment-emergent adverse events (TEAEs), and only rare serious adverse events (SAEs). The available safety and tolerability data on teriflunomide have been derived from the phase II clinical trial, its openlabel extension, and the subsequent phase III clinical trials (TEMSO, TOWER). ${ }^{39,40,46,48}$

In the phase II clinical trial, there was a similar incidence of TEAEs across the placebo and teriflunomide treatment arms. TEAEs that were more commonly reported in teriflunomide-treated patients included nasopharyngitis, alopecia, nausea, alanine aminotransferase (ALT) increase, paresthesia, back and limb pain, diarrhea, and arthralgia. Observed SAEs included elevated liver-function tests, hepatic dysfunction, neutropenia, rhabdomyolysis, and trigeminal neuralgia, and the incidence of these events was similar across the placebo and treatment arms. There was no significant difference in numbers of patients with significantly abnormal laboratory tests across treatment arms, but there was a higher frequency of TEAEs leading to study withdrawal in the high-dose teriflunomide treatment arm. ${ }^{39}$

Subsequently, the open-label extension (with up to 8.5 years' follow-up) of the phase II clinical trial confirmed the safety and tolerability profile observed in the double-blind phase of the study. The incidence of TEAEs was similar across teriflunomide treatment arms, with the exception of oral herpes infection, which was more common in the highdose teriflunomide treatment arm. Furthermore, the number

\begin{tabular}{lll}
\hline Treatment period & Primary/secondary outcomes & Study status \\
\hline I08 weeks & $\begin{array}{l}\text { Primary: ARR } \\
\text { Secondary: disability progression, fatigue, MRI outcomes }\end{array}$ & Decreased ARR in both Rx groups \\
& & Trend towards decreased disability progression in \\
& & mg Rx group \\
& & Decreased disability progression in I4 mg Rx group \\
Improved MRI outcomes in both Rx groups (possible & dose effect) \\
$48-202$ weeks & Primary: ARR & Decreased ARR in both Rx groups \\
& $\begin{array}{l}\text { Secondary: time to disability progression, change in fatigue, } \\
\text { change in health status }\end{array}$ & Decreased disability progression in I4 mg Rx group
\end{tabular}

48-174 weeks

288 weeks

48-152 weeks

108-300 weeks
Primary: time to failure (relapse or treatment discontinuation)

Secondary: ARR, fatigue, subject satisfaction

Primary: number of patients with adverse events Secondary: disability progression, ARR, MRI outcomes

Primary: ARR

Secondary: MRI outcomes, disability progression, time to

relapse, proportion relapse-free, fatigue, health status,

hospitalization due to relapse

Primary: conversion to CDMS by relapse

Secondary: conversion to CDMS by MRI criteria,

ARR, disability progression, MRI outcomes, fatigue
Recruitment complete, active

Recruitment complete, active

Recruiting

Recruiting 
of SAEs was similar across both doses of teriflunomide. Asymptomatic ALT increases $(\leq 3 \times$ upper limit of normal [ULN]) were common (7 mg, 64.2\%; $14 \mathrm{mg}, 62.1 \%$ ) and increases $>3 \times \mathrm{ULN}$ were similar across treatment groups (7 mg, 12.3\%; $14 \mathrm{mg}, 12.1 \%$ ). In individuals with significant increases, laboratory value normalization occurred within 2 months of treatment discontinuation in the majority of cases. There was a higher incidence of leukopenia observed in the $14 \mathrm{mg}$ teriflunomide treatment arm (3.7\% and $18.2 \%$ seen in the $7 \mathrm{mg}$ and $14 \mathrm{mg}$ groups, respectively), but the magnitude of the decrease in white blood cell count was low and did not lead to treatment discontinuation in any of the cases. ${ }^{40}$

In the reported open-label extension of the phase II clinical trial, ${ }^{40}$ there have been no reports of serious opportunistic infections or hypersensitivity reactions with teriflunomide use. In addition, the incidence of malignancy was similar to population-based estimates, with no pattern suggestive of immunosuppression-related malignancy. There was a single death due to a sudden cardiac disorder in the reported openlabel extension; ${ }^{40}$ however, an extensive safety evaluation concluded that it is difficult to attribute this death solely to teriflunomide, and that concomitant medical conditions and medications are likely to have contributed. ${ }^{40}$

Reassuringly, the safety and tolerability of teriflunomide in TEMSO was similar to what was observed in the phase II clinical trial and open-label extension, without the emergence of any new safety concerns and no reported deaths. Specifically, the incidence of AEs $(87.5 \%, 89.1 \%$, and $90.8 \%$, in placebo, $7 \mathrm{mg}$ teriflunomide, and $14 \mathrm{mg}$ teriflunomide, respectively) and SAEs $(12.8 \%, 14.1 \%$, and $15.9 \%$ in placebo, low-dose teriflunomide, and high-dose teriflunomide, respectively), were similar across treatment arms, as were AEs leading to study discontinuation $(8.1 \%, 9.8 \%$, and $10.9 \%$ in placebo, $7 \mathrm{mg}$ teriflunomide, and $14 \mathrm{mg}$ teriflunomide, respectively). AEs observed more frequently with teriflunomide treatment and associated with a dose effect included nausea, diarrhea, hair thinning or decreased hair density, and elevated ALT levels (seen in $35.9 \%$ of placebo, $54.0 \%$ of teriflunomide $7 \mathrm{mg}$, and $57.3 \%$ of teriflunomide $14 \mathrm{mg}$ patients). Reductions in neutrophil and lymphocyte counts were small in magnitude, and tended to stabilize within 3 months. In rare individuals with moderate neutropenia $(n=3)$, continued treatment resulted in spontaneous resolution in two patients, while in one patient there was resolution with discontinuation of teriflunomide. There were no deaths or serious opportunistic infections observed. ${ }^{46}$

Similarly, in TOWER, the total number of AEs, SAEs, and AEs leading to discontinuation were similar across the placebo, teriflunomide $7 \mathrm{mg}$, and $14 \mathrm{mg}$ treatment arms. AEs observed in TOWER were consistent with those reported in previous clinical trials with teriflunomide in MS, and the most common AEs reported more frequently in the teriflunomide treatment groups were headache, increase in ALT, hair thinning or alopecia, diarrhea, nausea, and neutropenia. There was no indication of increased infection in the teriflunomide treatment arms. There were four deaths reported in TOWER: three in the teriflunomide treatment arms and one in the placebo arm. The three deaths in the teriflunomide arms were due to suicide, a motor vehicle accident, and sepsis, while the death in the placebo arm was due to respiratory infection. ${ }^{48}$

Animal studies have demonstrated the teratogenic potential of leflunomide. ${ }^{51,52}$ Animal studies of teriflunomide have demonstrated embryotoxicity and teratogenicity; ${ }^{31}$ however, the teratogenic risk of teriflunomide in humans has not been well characterized due to limited experience. In light of leflunomide's known teratogenicity in animals, strict contraception is recommended for all females of reproductive age taking this drug, and males are cautioned not to father a child while on therapy, as teriflunomide may be transmitted in semen and the degree of transvaginal absorption is not well characterized.

In the teriflunomide clinical trials, women who became pregnant were required to undergo a cholestyramine or activated charcoal-based washout procedure after treatment discontinuation, and it was necessary to confirm that the plasma level was $<0.02 \mathrm{~g} / \mathrm{L}$, which is thought to be a level representing minimal risk in pregnancy. Without undergoing the washout procedure, it can take up to 2 years to achieve systemic clearance of teriflunomide that is at an acceptable level. ${ }^{39}$

In the phase II clinical trial, there were six pregnancies documented. Four patients chose to terminate the pregnancy, but two underwent the washout procedure as soon as they became aware of the pregnancy, and in both cases subsequently delivered healthy infants with no structural deficits or other health concerns. ${ }^{39}$ Similarly, in the phase III clinical trial, there were eleven pregnancies reported, with four spontaneous abortions and six induced abortions. One patient in the $14 \mathrm{mg}$ teriflunomide treatment arm had been on teriflunomide for 31 days of her pregnancy, underwent the washout procedure, and delivered a healthy child with no significant health concerns. ${ }^{46}$

A recent cohort study evaluated the safety of leflunomide in 64 RA patients, and did not find an increase in structural AEs in infants. ${ }^{53}$ Another study evaluating 45 patients 
exposed to leflunomide during pregnancy or preconception resulted in two children with structural anomalies; however, there was a potential alternate etiology identified for at least some of the observed defects..$^{54} \mathrm{~A}$ recent analysis of 65 pregnancies reported in all clinical trials of teriflunomide to date found no structural or functional deficits in any newborns with prenatal teriflunomide exposure following elimination. Furthermore, the proportion of spontaneous abortions was within population-based norms. ${ }^{55}$ Although these studies are somewhat reassuring for women who become inadvertently pregnant while on leflunomide or teriflunomide, at the present time, in the absence of any definitive clinical data, teriflunomide's teratogenic potential remains a significant concern. Thus, for the time being, individuals taking teriflunomide should practice strict contraception.

The availability of long-term safety data on leflunomide can further supplement the safety and tolerability profile of teriflunomide. Overall, postmarketing surveillance of leflunomide suggests that its safety profile is acceptable. Nausea, diarrhea, and alopecia are the most commonly reported AEs, but these events rarely lead to medication discontinuation. However, leflunomide does have associated rare SAEs, including hepatic toxicity, which is uncommonly seen. In addition, rarer SAEs include peripheral neuropathy, hypertension, pneumonitis, and cytopenia. ${ }^{56}$ There have been two cases of progressive multifocal leukoencephalopathy reported in the context of approximately 2.1 million years of leflunomide use. One of these cases was reported in a patient who had previously been on five other immunosuppressants: azathioprine, chloroquine, danazol, cyclosporin A,

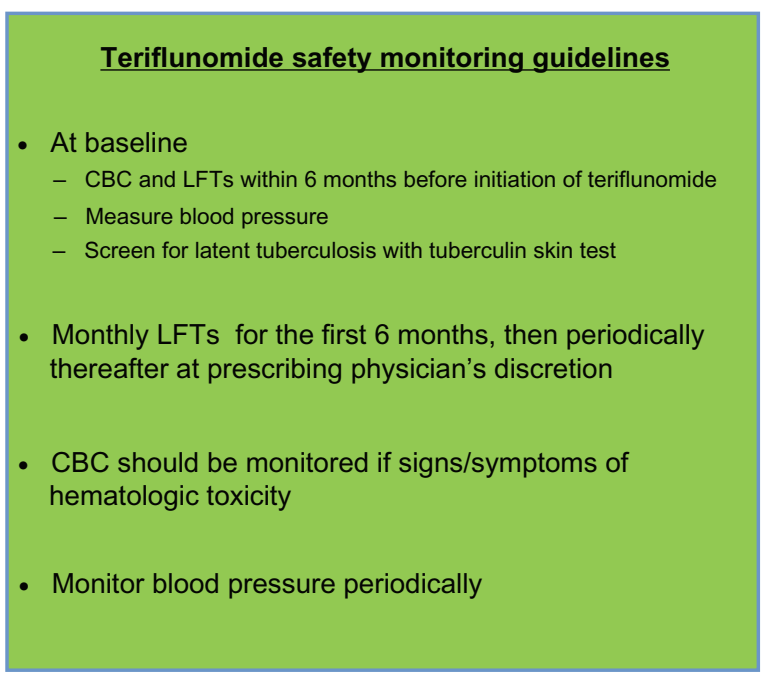

Figure 3 Teriflunomide safety-monitoring guidelines.

Abbreviations: CBC, complete blood count; LFTs, liver-function tests (aspartate transaminase, alanine transaminase, alkaline phosphatase, bilirubin). and methotrexate. ${ }^{57}$ The second case was a patient who had previously been on azathioprine..$^{58}$

Although teriflunomide's safety profile based on the existing clinical trials has been relatively benign, given the rare SAEs seen with long-term safety data available from leflunomide, a high degree of vigilance should be practiced when monitoring patients on this novel DMA. ${ }^{57}$

Current FDA safety-monitoring guidelines for teriflunomide recommend obtaining a baseline complete blood count and liver function tests (transaminases and bilirubin) within 6 months before initiation of teriflunomide, and monitoring monthly liver-function tests for 6 months after initiation of therapy. Subsequent liver-function testing should be performed at the discretion of the prescribing physician. Complete blood count should be monitored if there are any signs or symptoms of hematologic toxicity. A baseline blood pressure should also be obtained, and blood pressure should be monitored periodically thereafter. Prior to teriflunomide initiation, the FDA also recommends that patients should be screened for latent tuberculosis infection with a tuberculin skin test; positive cases should be treated according to the standard of care prior to initiation of teriflunomide (Figure 3).

\section{Conclusion}

Teriflunomide shows promise as a relatively safe and efficacious oral DMA in the treatment of relapsing MS, both as monotherapy or as an add-on agent. The convenience of oral administration makes teriflunomide an attractive agent to add to the available treatment armamentarium of relapsing MS. Furthermore, existing experience with a closely related drug, leflunomide, gives teriflunomide the added benefit of indirect long-term safety data, which is of considerable benefit, since long-term safety is ultimately one of the most important factors that determine the clinical utility of a drug in the treatment of MS.

Although only head-to-head clinical trials with other existing therapies can provide more definitive evidence of teriflunomide's relative efficacy to other DMAs, based on currently available data, teriflunomide appears likely to have similar efficacy to existing first-line treatments (IFN- $\beta$ and GA) as monotherapy, but has the added convenience of oral administration. In addition, teriflunomide appears to demonstrate efficacy as an add-on agent to first-line DMAs. Thus, the use of teriflunomide in the "real world" will likely be as a first-line monotherapy agent. Theoretically, teriflunomide might be considered for use as an add-on therapy in patients with suboptimal responses to first-line injectable DMAs who are reluctant or unable to use other approved DMAs. However, cost would be a significant 
issue in this setting, and would greatly reduce the probability of this happening in day-to-day practice.

Results from ongoing large-scale phase III clinical trials will provide additional information on the efficacy and tolerability of teriflunomide. Possible concerns requiring further clarification include teriflunomide's potential teratogenicity and unknown potential for malignancy or serious infectious complications. In addition, the long washout period of teriflunomide may have implications for the use of other immunosuppressive agents in individuals with breakthrough disease on this drug, although rapid-elimination procedures may mitigate this concern. Most importantly, as with any novel pharmacological agent, postmarketing surveillance will be essential in more definitively characterizing the long-term safety and efficacy of teriflunomide in the treatment of MS in the real world.

\section{Disclosure}

Dr Jiwon Oh has received educational grant support from Teva Neurosciences and consulting fees from EMD-Serono. Dr Paul O'Connor has received personal compensation (for consulting, serving on a scientific advisory board, or speaking) or grant support (for scholarly activities) from pharmaceutical companies that develop products for MS, including Actelion, Biogen Idec, Celgene, Genzyme, Sanofi-Aventis, EMD Merck Serono, Abbott Labs, Teva Pharmaceuticals, Bayer, Genentech, Lilly, Roche, and Novartis. Dr O'Connor receives consultation fees from the MS Society of Canada, and has received grant support from the MS Society of Canada, the NIH, and Direct MS.

\section{References}

1. Marriott JJ, O'Connor PW. Emerging therapies in relapsing-remitting multiple sclerosis. Rev Recent Clin Trials. 2010;5:179-188.

2. Osiri M, Shea B, Robinson V, et al. Leflunomide for treating rheumatoid arthritis. Cochrane Database Syst Rev. 2003;1:CD002047.

3. Bartlett RR, Schleyerbach R. Immunopharmacological profile of a novel isoxazol derivative, HWA 486, with potential antirheumatic activity - I. Disease modifying action on adjuvant arthritis of the rat. Int J Immunopharmacol. 1985;7:7-18.

4. Korn T, Magnus T, Toyka K, Jung S. Modulation of effector cell functions in experimental autoimmune encephalomyelitis by leflunomide - mechanisms independent of pyrimidine depletion. J Leukoc Biol. 2004;76:950-960.

5. Posevitz V. Teriflunomide selectively suppresses antigen induced $T$ cell expansion in a TCR avidity dependent fashion. Paper presented at the 28th Congress of the European Committee for Treatment and Research in Multiple Sclerosis (ECTRIMS); October 10-13, 2012; Lyon, France.

6. Bruneau JM, Yea CM, Spinella-Jaegle S, et al. Purification of human dihydro-orotate dehydrogenase and its inhibition by A77 1726, the active metabolite of leflunomide. Biochem J. 1998;336:299-303.

7. Cherwinski HM, Cohn RG, Cheung P, et al. The immunosuppressant leflunomide inhibits lymphocyte proliferation by inhibiting pyrimidine biosynthesis. J Pharmacol Exp Ther. 1995;275:1043-1049.
8. Fox RI, Herrmann ML, Frangou CG, et al. Mechanism of action for leflunomide in rheumatoid arthritis. Clin Immunol. 1999;93: 198-208.

9. Ruckemann K, Fairbanks LD, Carrey EA, et al. Leflunomide inhibits pyrimidine de novo synthesis in mitogen-stimulated T-lymphocytes from healthy humans. J Biol Chem. 1998;273:21682-21691.

10. Herrmann ML, Schleyerbach R, Kirschbaum BJ. Leflunomide: an immunomodulatory drug for the treatment of rheumatoid arthritis and other autoimmune diseases. Immunopharmacology. 2000;47:273-289.

11. Fairbanks LD, Bofill M, Ruckemann K, Simmonds HA. Importance of ribonucleotide availability to proliferating T-lymphocytes from healthy humans. Disproportionate expansion of pyrimidine pools and contrasting effects of de novo synthesis inhibitors. J Biol Chem. 1995;270:29682-29689.

12. Elder RT, Xu X, Williams JW, Gong H, Finnegan A, Chong AS. The immunosuppressive metabolite of leflunomide, A77 1726, affects murine $\mathrm{T}$ cells through two biochemical mechanisms. J Immunol. 1997;159:22-27.

13. Korn T, Toyka K, Hartung HP, Jung S. Suppression of experimental autoimmune neuritis by leflunomide. Brain. 2001;124:1791-1802.

14. Siemasko K, Chong AS, Jack HM, Gong H, Williams JW, Finnegan A. Inhibition of JAK 3 and STAT6 tyrosine phosphorylation by the immunosuppressive drug leflunomide leads to a block in IgG1 production. J Immunol. 1998;160:1581-1588.

15. Xu X, Williams JW, Bremer EG, Finnegan A, Chong AS. Inhibition of protein tyrosine phosphorylation in $\mathrm{T}$ cells by a novel immunosuppressive agent, leflunomide. J Biol Chem. 1995;270:12398-12403.

16. Hoskin DW, Taylor RM, Makrigiannis AP, James H, Lee TD. Dose-dependent enhancing and inhibitory effects of A77 1726 (leflunomide) on cytotoxic T lymphocyte induction. Int J Immunopharmacol. 1998;20:505-513.

17. Manna SK, Aggarwal BB. Immunosuppressive leflunomide metabolite (A77 1726) blocks TNF-dependent nuclear factor-kappa B activation and gene expression. J Immunol. 1999;162:2095-2102.

18. González-Alvaro I, Ortiz AM, Domínguez-Jiménez C, Aragón-Bodi A, Díaz Sánchez B, Sánchez-Madrid F. Inhibition of tumour necrosis factor and IL-17 production by leflunomide involves the JAK/STAT pathway. Ann Rheum Dis. 2009;68:1644-1650.

19. Mattar T, Kochhar K, Bartlett R, Bremer EG, Finnegan A. Inhibition of the epidermal growth factor receptor tyrosine kinase activity by leflunomide. FEBS Lett. 1993;334:161-164.

20. Manna SK, Mukhopadhyay A, Aggarwal BB. Leflunomide suppresses TNF-induced cellular responses: effects on NF-kappa B, activator protein-1, c-Jun N-terminal protein kinase, and apoptosis. J Immunol. 2000;165:5962-5969.

21. Hamilton LC, Vojnovic I, Warner TD. A771726, the active metabolite of leflunomide, directly inhibits the activity of cyclo-oxygenase-2 in vitro and in vivo in a substrate-sensitive manner. Br J Pharmacol. 1999;127:1589-1596.

22. Jankovic V, Samardzic T, Stosic-Grujicic S, Popadic D, Trajkovic V. Cell-specific inhibition of inducible nitric oxide synthase activation by leflunomide. Cell Immunol. 2000;199:73-80.

23. Zeyda M, Poglitsch M, Geyeregger R, et al. Disruption of the interaction of $\mathrm{T}$ cells with antigen-presenting cells by the active leflunomide metabolite teriflunomide: involvement of impaired integrin activation and immunologic synapse formation. Arthritis Rheum. 2005;52:2730-2739.

24. Layseca-Espinosa E, Pedraza-Alva G, Montiel JL, et al. T cell aggregation induced through CD43: intracellular signals and inhibition by the immunomodulatory drug leflunomide. J Leukoc Biol. 2003;74:1083-1093.

25. Dimitrova P, Skapenko A, Herrmann ML, Schleyerbach R, Kalden JR, Schulze-Koops H. Restriction of de novo pyrimidine biosynthesis inhibits Th1 cell activation and promotes Th2 cell differentiation. J Immunol. 2002;169:3392-3399. 
26. Deage V, Burger D, Dayer JM. Exposure of T lymphocytes to leflunomide but not to dexamethasone favors the production by monocytic cells of interleukin-1 receptor antagonist and the tissueinhibitor of metalloproteinases-1 over that of interleukin-1beta and metalloproteinases. Eur Cytokine Netw. 1998;9:663-668.

27. Cutolo M, Sulli A, Ghiorzo P, Pizzorni C, Craviotto C, Villaggio B. Anti-inflammatory effects of leflunomide on cultured synovial macrophages from patients with rheumatoid arthritis. Ann Rheumatic Dis. 2003;62:297-302.

28. Kraan MC, de Koster BM, Elferink JG, Post WJ, Breedveld FC, Tak PP. Inhibition of neutrophil migration soon after initiation of treatment with leflunomide or methotrexate in patients with rheumatoid arthritis: findings in a prospective, randomized, double-blind clinical trial in fifteen patients. Arthritis Rheum. 2000;43:1488-1495.

29. Kraan MC, Reece RJ, Barg EC, et al. Modulation of inflammation and metalloproteinase expression in synovial tissue by leflunomide and methotrexate in patients with active rheumatoid arthritis. Findings in a prospective, randomized, double-blind, parallel-design clinical trial in thirty-nine patients at two centers. Arthritis Rheum. 2000;43:1820-1830.

30. Fuentealba RA, Marasa J, Diamond MI, Piwnica-Worms D, Weihl CC. An aggregation sensing reporter identifies leflunomide and teriflunomide as polyglutamine aggregate inhibitors. Hum Mol Genet. 2012;21:664-680.

31. Sanofi. Teriflunomide [data on file]. Paris, France: Sanofi; 2012.

32. Limsakun T, Menguy-Vacheron F, Mazarin C. Pharmacokinetics of oral teriflunomide, a novel oral disease-modifying agent under investigation for the treatment of multiple sclerosis. Programs and abstracts of the 62nd American Academy of Neurology Annual Meeting; April 10-17, 2010; Toronto, ON, Canada.

33. Tallantyre E, Evangelou N, Constantinescu CS. Spotlight on teriflunomide. Int MS J. 2008;15:62-68.

34. Storch MK, Stefferl A, Brehm U, et al. Autoimmunity to myelin oligodendrocyte glycoprotein in rats mimics the spectrum of multiple sclerosis pathology. Brain Pathol. 1998;8:681-694.

35. Weissert R, Wallström E, Storch MK, et al. MHC haplotype-dependent regulation of MOG-induced EAE in rats. J Clin Invest. 1998;102: 1265-1273.

36. Korn T, Mitsdoerffer M, Kuchroo VK. Immunological basis for the development of tissue inflammation and organ-specific autoimmunity in animal models of multiple sclerosis. Results Probl Cell Differ. 2010;51: 43-74.

37. Merrill JE, Hanak S, Pu SF, et al. Teriflunomide reduces behavioral, electrophysiological, and histopathological deficits in the Dark Agouti rat model of experimental autoimmune encephalomyelitis. J Neurol 2009;256:89-103.

38. Styren S, Barbier A, Selk D, Wettstein JG. Beneficial effects of teriflunomide in experimental allergic encephalomyelitis. Paper presented at Society for Neuroscience Annual Meeting; October 23-27, 2004; San Diego, CA, USA.

39. O'Connor PW, Li D, Freedman MS, et al. A phase II study of the safety and efficacy of teriflunomide in multiple sclerosis with relapses. Neurology. 2006;66:894-900.

40. Confavreux C, Li DK, Freedman MS, et al. Long-term follow-up of a phase 2 study of oral teriflunomide in relapsing multiple sclerosis: safety and efficacy results up to 8.5 years. Mult Scler. 2012;18:1278-1289.

41. Freedman MS, Wolinsky JS, Wamil B, et al. Teriflunomide added to interferon-beta in relapsing multiple sclerosis: a randomized phase II trial. Neurology. 2012;78:1877-1885.

42. Freedman MS, WJ, Frangin GA, et al. Oral teriflunomide or placebo added to glatiramer acetate for 6 months in patients with relapsing multiple sclerosis: safety and efficacy results. Programs and abstracts of the 62nd American Academy of Neurology Annual Meeting; April 10-17, 2010; Toronto, ON, Canada.

43. Sanofi. Efficacy and safety of teriflunomide in patients with relapsing multiple sclerosis and treated with interferon-beta (TERACLES). 2012. Available from: http://clinicaltrials.gov/ct2/show/NCT01252355?term=t eriflunomide\&rank=3. Accessed October 30, 2012.
44. Sanofi. Long term safety of teriflunomide when added to interferon-beta or glatiramer acetate in patients with multiple sclerosis. 2012. Available from: http://clinicaltrials.gov/ct2/show/NCT00811395?term=terifluno mide\&rank=4. Accessed October 30, 2012.

45. Bar-Or A, Freedman MS, Kremenchutzky F, et al. Effect of teriflunomide on immune responses to seasonal influenza vaccination in patients with relapsing multiple sclerosis: results from the TERIVA study. Paper presented at the 28th Congress of the European Committee for Treatment and Research in Multiple Sclerosis (ECTRIMS); October 10-13, 2012; Lyon, France.

46. O'Connor P, Wolinsky JS, Confavreux C, et al. Randomized trial of oral teriflunomide for relapsing multiple sclerosis. N Engl J Med. 2011;365: 1293-1303.

47. Sanofi. Long term safety and efficacy study of teriflunomide $7 \mathrm{mg}$ or $14 \mathrm{mg}$ in patients with relapsing-remitting multiple sclerosis. 2012. Available from: http:/clinicaltrials.gov/ct2/show/NCT00803049?ter $\mathrm{m}=$ teriflunomide\&rank=13. Accessed October 30, 2012.

48. Kappos L, Comi G, Confavreux C, et al. The efficacy and safety of teriflunomide in patients with relapsing MS: results from TOWER, a phase III, placebo-controlled study. Paper presented at the 28th Congress of the European Committee for Treatment and Research in Multiple Sclerosis (ECTRIMS); October 10-13, 2012; Lyon, France.

49. Vermersch P, Czlonkowska A, Grimaldi LME, et al. A multicenter, randomized, parallel-group, rater-blinded study comparing the effectiveness and safety of teriflunomide and subcutaneous interferon beta- $1 \mathrm{a}$ in patients with relapsing multiple sclerosis. Paper presented at the 28th Congress of the European Committee for Treatment and Research in Multiple Sclerosis (ECTRIMS); October 10-13, 2012; Lyon, France.

50. Sanofi. Phase III study with teriflunomide versus placebo in patients with first clinical symptom of multiple sclerosis (TOPIC). 2012. Available from: http://clinicaltrials.gov/ct2/show/ NCT00622700?term=TOPIC\&rank=1. Accessed October 30, 2012.

51. Brent RL. Teratogen update: reproductive risks of leflunomide (Arava); a pyrimidine synthesis inhibitor: counseling women taking leflunomide before or during pregnancy and men taking leflunomide who are contemplating fathering a child. Teratology. 2001;63:106-112.

52. Fukushima R, Kanamori S, Hirashiba M, et al. Teratogenicity study of the dihydroorotate-dehydrogenase inhibitor and protein tyrosine kinase inhibitor Leflunomide in mice. Reprod Toxicol. 2007;24:310-316.

53. Chambers CD, Johnson DL, Robinson LK, et al. Birth outcomes in women who have taken leflunomide during pregnancy. Arthritis Rheum. 2010;62:1494-1503.

54. Cassina M, Johnson DL, Robinson LK, et al. Pregnancy outcome in women exposed to leflunomide before or during pregnancy. Arthritis Rheum. 2012;64:2085-2094.

55. Kieseier B, Benamor M, Benzerdjeb H, Stüve O. Pregnancy outcomes from the teriflunomide clinical development programme: retrospective analysis of the teriflunomide clinical trial database. Paper presented at the 28th Congress of the European Committee for Treatment and Research in Multiple Sclerosis (ECTRIMS); October 10-13, 2012; Lyon, France.

56. White DH, Lynskey NV, Jones PB. Leflunomide use in New Zealand. A national prospective post-marketing study. Intern Medicine J. 2009;39: 95-102.

57. Warnatz K, Peter HH, Schumacher M, et al. Infectious CNS disease as a differential diagnosis in systemic rheumatic diseases: three case reports and a review of the literature. Ann Rheumatic Dis. 2003;62:50-57.

58. Rahmlow M, Shuster EA, Dominik J, et al. Leflunomide-associated progressive multifocal leukoencephalopathy. Arch Neurol. 2008;65: 1538-1539.

59. Gold R, Wolinsky JS. Pathophysiology of multiple sclerosis and the place of teriflunomide. Acta Neurol Scand. 2011;124:75-84. 


\section{Publish your work in this journal}

Therapeutics and Clinical Risk Management is an international, peerreviewed journal of clinical therapeutics and risk management, focusing on concise rapid reporting of clinical studies in all therapeutic areas, outcomes, safety, and programs for the effective, safe, and sustained use of medicines. This journal is indexed on PubMed Central, CAS,

EMBase, Scopus and the Elsevier Bibliographic databases. The manuscript management system is completely online and includes a very quick and fair peer-review system, which is all easy to use. Visit http://www.dovepress.com/testimonials.php to read real quotes from published authors.

Submit your manuscript here: http://www.dovepress.com/therapeutics-and-clinical-risk-management-journal 